\title{
Elimination of misrun and gas hole defects of investment casting TiAl alloy turbocharger based on numerical simulation and experimental study
}

\author{
Jun Zhao ${ }^{1,2}$, *Zhi-yong Zhang ${ }^{1,2}$, Shi-bing Liu ${ }^{1,2}$, Kun Shi ${ }^{1,2}$, Chun-ling Bao ${ }^{1,2}$, Zhao-sheng Ning ${ }^{1,2}$, Ping Yan ${ }^{1,2}$, \\ Lei Wang ${ }^{3}$, Yan-chun Lou', \\ 1. State Key Laboratory of Light Alloy Casting Technology for High-end Equipment, Shenyang 110022, China \\ 2. Shenyang Research Institute of Foundry Co., Ltd., Shenyang 110022, China \\ 3. Northeastern University, Shenyang 110189, China
}

\begin{abstract}
Casting technology of thin-wall TiAl alloy turbochargers was studied by investment casting and numerical simulation. Misruns and gas holes were the main defects observed in preliminary work due to the poor fluidity of alloy, and to gas entrapment. In order to eliminate these defects, cast parameters, such as centrifugal rotation rate and mould preheating temperature, were optimized by numerical simulation, meanwhile, the structure of the shell mould was optimized to improve the filling capacity of TiAl alloy. Pouring experiments were carried out by vacuum induction melting furnace equipped with a water-cooled copper crucible based on the above optimization. The quality of the TiAl alloy casting was analyzed by fluorescent penetrant inspection and X-ray detection. The results show that a centrifugal rotation rate of $200 \mathrm{rpm}$, mould preheating temperature of $600{ }^{\circ} \mathrm{C}$, shell preparation through organic fiber addition can dramatically improve the mould filling capacity, and integrated turbochargers were finally prepared.
\end{abstract}

Key words: titanium aluminide; cast defects; turbocharger; investment casting

CLC numbers: TG146.23 Document code: A

Article ID: 1672-6421(202001-029-06

$\mathrm{T}$ Al intermetallic alloys, having a low density, excellent high-temperature properties and oxidation resistance, are potential substitute materials for nicklebased superalloys ${ }^{[1-6]}$. Ti-48Al-2Cr-2Nb(Ti-4822) is a conventional TiAl alloy, with a service temperature below $750{ }^{\circ} \mathrm{C}$. GE Corporation has applied Ti-4822 alloy to the 6th and 7th Low Pressure Turbine Blades (LPTB) in Boeing 787 aircraft engines, which induced a 200 pound weight reduction, $15 \%$ energy conservation and $50 \%$ reduction of noxious NOx emissions ${ }^{[7-11]}$. Hightemperature TiAl alloys generally contain much more beta phase stabilizing elements, such as $\mathrm{Nb}, \mathrm{V}, \mathrm{Mo}, \mathrm{Mn}$, etc. ${ }^{[12-19]}$. The solution strengthening of these elements could raise the solidus and the high-temperature yield strength of TiAl alloys. $\mathrm{Nb}$ has attracted attention for years because high- $\mathrm{Nb}$ content could increase oxidation resistance dramatically, i.e., TiAl alloys with 6-10 at.\%

\section{*Zhi-yong Zhang}

Male, born in 1982, Senior Engineer, Ph.D. His research interests mainly focus on investment casting process of advanced titanium alloys and titanium aluminide alloys.

E-mail: ustbamm2011@126.com

Received: 2019-04-28; Accepted: 2019-11-11
$\mathrm{Nb}^{[20-23]}$, which were expected to be used up to $900{ }^{\circ} \mathrm{C}$. It has the potential to enlarge application toward a higher service temperature, as is meaningful for further weight reduction for aircraft engines.

TiAl alloys have poor hot working performance; among feasible processing methods, investment casting is a more economical and near-net-shape method, which can produce convoluted shape parts with a fine surface quality ${ }^{[24]}$. However, TiAl alloy has poor liquidity, a high rate of solidification shrinkage, and thus, the cast quality of thin-walled TiAl alloy parts was hard to control. Centrifugal casting and mould preheating have been proved effective to improve mould filling capacities. Yang L et al. ${ }^{[25]}$ studied the castability of Ti-45Al-8Nb alloy through pouring small turbine blade. Results showed that misrun defects located at the thinnest trailing edge, furthermore, the shrinkage porosities of gravity casting were more in number and more dispersed compared to centrifugal casting. $\mathrm{Su}$ et al. ${ }^{[26]}$ measured the shrinkage rate of TiAl alloy, and found that the shrinkage rate varied from $1.35 \%$ to $1.89 \%$ corresponding to pouring temperature from $1,595{ }^{\circ} \mathrm{C}$ to $1,685{ }^{\circ} \mathrm{C}$. High pouring temperature and centrifugal casting process were also suggested to 
eliminate misrun defects, and potential problems such as contamination of casting surface and safety must be carefully addressed. Wan Y B ${ }^{[27]}$ pointed out that gas defects of TiAl alloy were invasive gas hole, reactive gas pore and precipitated gas pore. If the filling speed of molten metal is fast, it's easy to engulf protective argon gas to form invasive gas hole in the casting. Pedor et al. ${ }^{[28]}$ suggested that the increase in mould temperature can result in a better castability for investment casting. Therefore, centrifugal casting parameters including rotation rate and mould preheating are crucial to this study and need further optimization.

In this study, high-Nb TiAl alloy thin-walled turbocharger wheels were prepared by centrifugal investment casting. Firstly, in order to simplify the experimental process, numerical simulation with ProCAST software was applied to optimize casting parameters including mould preheating temperature and centrifugal rotation rate. Secondly, organic fibers were added to the ceramic shell to improve gas permeability ${ }^{[29]}$. Lastly, casting experiments were carried out to verify the simulation results.

\section{Experimental procedure}

The alloy used in this study was Ti-46Al-6.5Nb-0.6Cr-0.2Ni, which were all atom percentages unless noted otherwise. The alloy was remelted twice by vacuum induction melting furnace equipped with a water-cooled copper crucible, and was poured into the ceramic shell moulds. Zirconia was chosen as the shell surface material, and alumino-silicate was selected as the back-up coating. The outside dimension of turbocharger is $\Phi 52 \mathrm{~mm} \times 30 \mathrm{~mm}$, the thinnest part is $0.6 \mathrm{~mm}$.

To avoid aluminium evaporation, TiAl alloy was generally remelted and cast under argon atmosphere. Therefore, ceramic shell for this kind of alloy should be produced through which gas can permeate, otherwise, gas entrapment will lead to misrun and gas hole defects for the thin-walled castings. In order to increase the permeability of shell mould, organic fibers $(0,0.5,1$ and $1.5 \mathrm{wt} . \%)$ were added into the stucco of back layer. After back layers were coated, the ceramic mould was fired above $1,000{ }^{\circ} \mathrm{C}$, and the fibers were burned out to form a porous structure.

The turbochargers prepared by investment casting under gravity without shell preheating are shown in Fig. 1. It can be seen that misrun and gas hole are the main defects. In order to improve the casting quality, ProCAST software was used to simulate the filling and solidification processes. The wax pattern of a single turbocharger with a pouring cup was designed and is shown in Fig. 2. In order to select suitable casting parameters, different centrifugal rotation rates $(0,100,200,300 \mathrm{rpm})$ and mould temperatures $\left(25,400,600,800{ }^{\circ} \mathrm{C}\right)$ were selected. The simulation results were analyzed from aspects of temperature field, solid fraction, solidification time, and free surface of liquid metal. The shell porosity was detected by the water saturation method, and the shell strength was measured by a three-point bending experiment. Then, castings were produced based on the numerical simulation results. Casting qualities were analyzed by $\mathrm{X}$-ray defect detection and fluorescence detection.

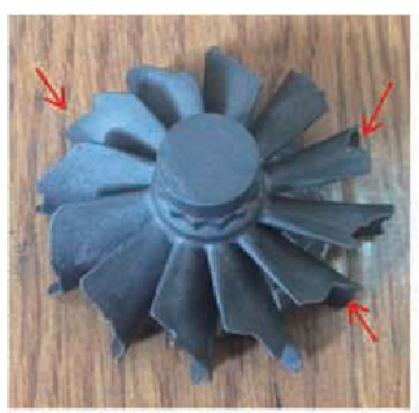

Misrun

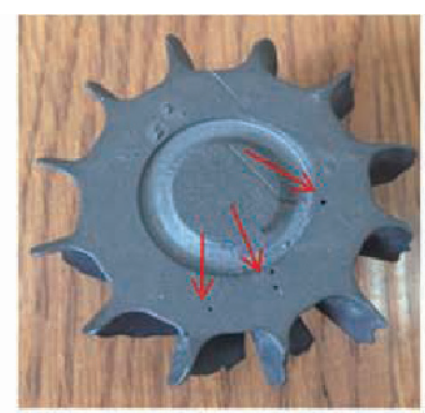

Gas hole

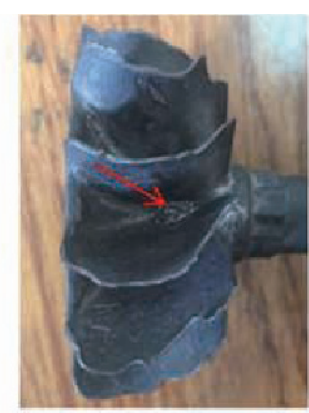

Sand inclusion

Fig. 1: Cast defects of TiAl alloy turbocharger before process optimization
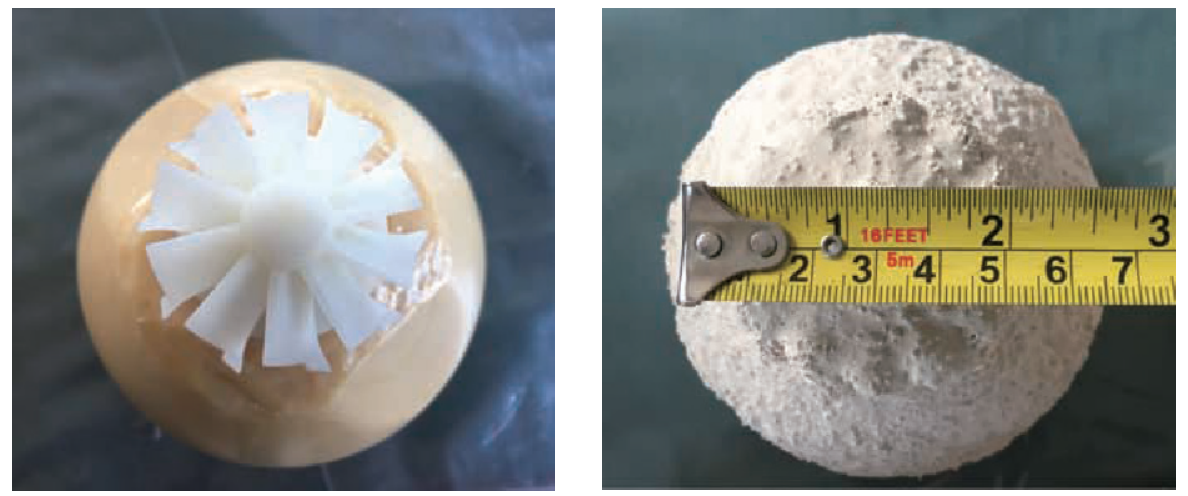

Fig. 2: Wax pattern and shell mould of a single turbocharger 


\section{Results}

\subsection{Effect of shell preheating temperature on filling process}

Figures 3(a) to (c) show the temperature field of the turbocharger wheel solidified without shell preheating. It can be seen that the wheel tips firstly solidified at $1.08 \mathrm{~s}$, and the wheel completely solidified at $2.69 \mathrm{~s}$, which was also proved by solid fraction distribution at $2.69 \mathrm{~s}$ in Fig. 3(d). The filling and solidification processes of these thin-walled wheels were very rapid due to the mould chilling effect. Many studies suggested that mould preheating and increasing pouring temperature can promote mould filling capacity ${ }^{[30]}$. However, during the water-cooled crucible remelting, a high melt superheat can hardly be obtained because heat of the TiAl alloy melt was partly transferred to water by heat conduction. It is difficult to increase filling capacity by increasing pouring

(a)

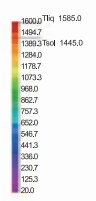

$y$

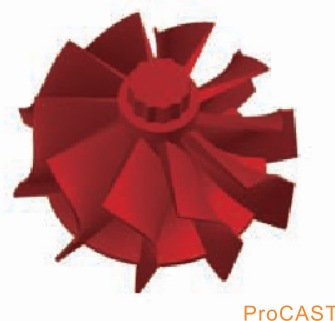

(c)
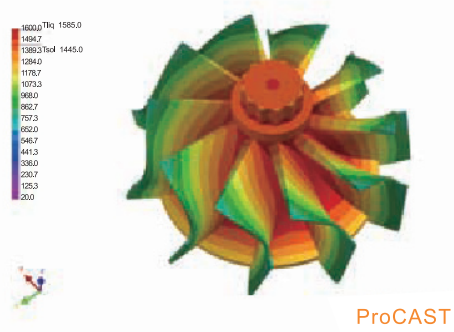

temperature, thus, increasing mould preheating temperature was the only parameter considered. Figure 4 shows slice profiles of solidification time of the turbocharger wheel at various mould preheating temperatures. The solidification time of the wheels ranged from $0.3 \mathrm{~s}$ to $6 \mathrm{~s}$. When the mould preheating temperature increases from $25^{\circ} \mathrm{C}$ to $800{ }^{\circ} \mathrm{C}$, the solidification time of the turbocharger wheel increases, suggesting that the liquid metal has more time to fill the wheel tips before solidification. Although increasing the shell preheating temperature can improve filling capacity of the molten metal, the interface reaction between ceramic mould and liquid metal should be considered. Therefore, $800{ }^{\circ} \mathrm{C}$ was not used in the following experiment validation. Meanwhile, insufficient preheating temperature, such as $400{ }^{\circ} \mathrm{C}$, cannot effectively eliminate misrun defects. Thus, $600{ }^{\circ} \mathrm{C}$ was considered appropriate for the optimized preheating temperature in this study. (b)
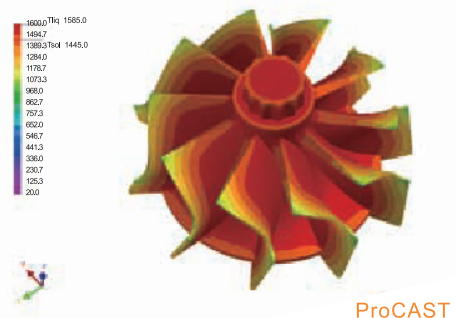

(d)

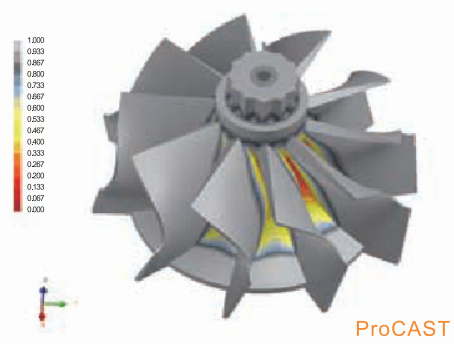

Fig. 3: Temperature fields at $0.2 \mathrm{~s} \mathrm{(a),} 1.08 \mathrm{~s}$ (b), $2.69 \mathrm{~s}$ (c) and solid fraction at 2.69 (d) of TiAl alloy turbocharger

(a)

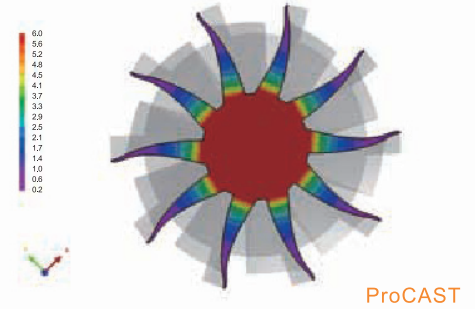

(c)

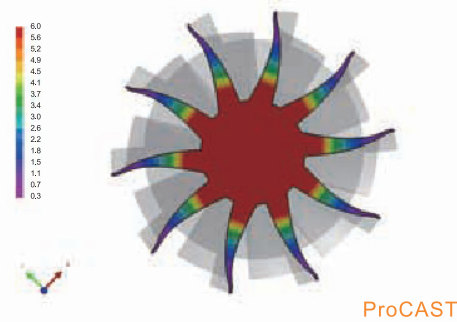

(b)

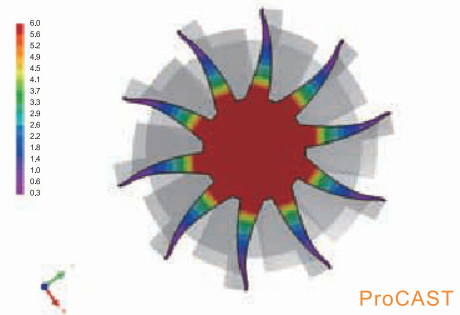

(d)

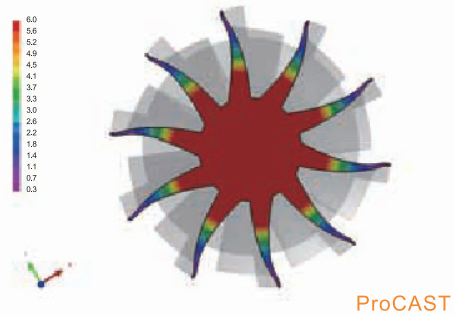

Fig. 4: Solidification times of TiAl turbocharger at various mould preheating temperatures: (a) $25^{\circ} \mathrm{C}$; (b) $400^{\circ} \mathrm{C}$; (c) $600{ }^{\circ} \mathrm{C}$; (d) $800^{\circ} \mathrm{C}$ 


\subsection{Confirmation of rotational rate of centrifugal casting}

Figure 5 shows the effect of rotational rates on the filling process. As the rotational rate increases from 0 to $300 \mathrm{rpm}$, the average pressure of free surface increases from 1.69 bar to 1.92 bar, meanwhile, the average flow velocity of free surface increases from $0.75 \mathrm{~m} / \mathrm{s}$ to $1.25 \mathrm{~m} / \mathrm{s}$. The change of centrifugal force of liquid metal with the increase of rotational rate can be described by $F=0.011 m R n^{2}$, where $F$ is centrifugal force, $m$ is mass of liquid metal, $R$ is rotation radius, and $\mathrm{n}$ is rotational rate. Filling capacity of TiAl alloy melt was enhanced by centrifugal force, especially, a high rotational rate promoted liquid metal to fill the wheel tips. However, for the simple pouring system in this study, the rotation vector was vertical to the gravity vector, a high rotational rate would weaken the feeding effect of the pouring cup, which would lead to shrinkage porosity in the wheel center. Both liquid feeding and filling capacity should be considered. Thus, $200 \mathrm{rpm}$ was chosen in the following experiment, because a rotational rate of $100 \mathrm{rpm}$ was insufficient to improve the filling capacity of molten metal, and $300 \mathrm{rpm}$ was too high to avoid solidification defects in the wheel center; meanwhile, a high rotational rate allowed for easy entrapment of the invasive gas hole.

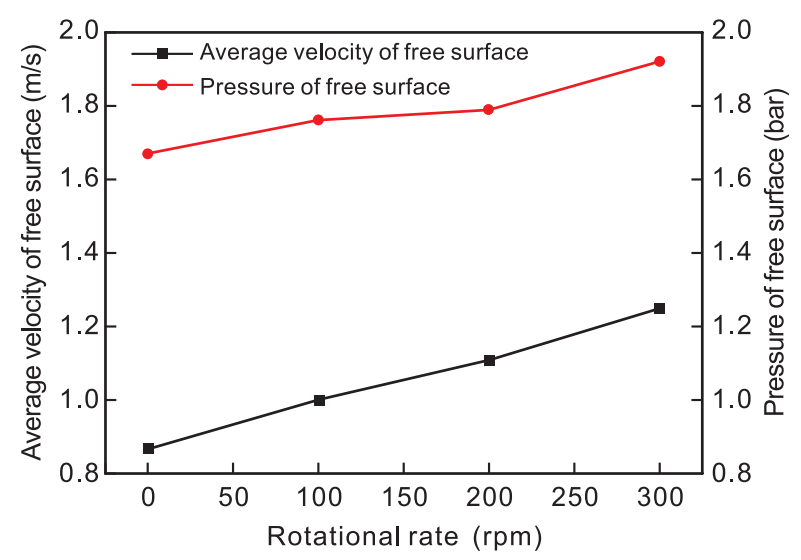

Fig. 5: Effect of rotational rates on filling process

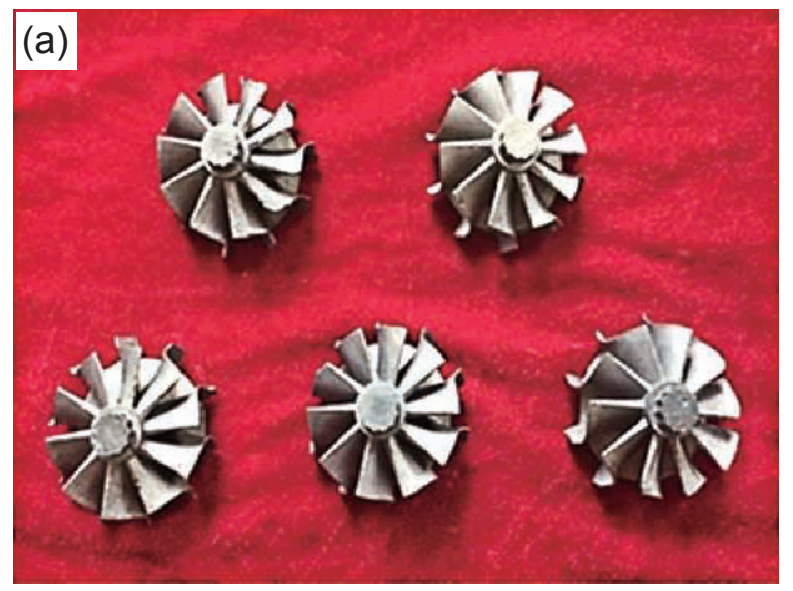

\subsection{Effect of fiber contents on shell porosity and strength}

The porosity and strength of shell specimens with different contents of fibers are shown in Table 1. As the fiber content increases from 0 to $1.5 \mathrm{wt} . \%$, the porosity of the shell mould increases from $25 \%$ to $39 \%$, while the strength decreases from 5.25 MPa to $2.33 \mathrm{MPa}$. Because the porosity of the shell with $0.5 \mathrm{wt} . \%$ fibers does not obviously increase, and $1.5 \mathrm{wt} . \%$ fibers addition lead to a dramatic descrease of shell strength, the ceramic shell containing $1 \mathrm{wt} . \%$ organic fibers with balanced strength and porosity was finally used in the casting experiment.

Table 1: Effect of fiber contents on shell porosity and strength

\begin{tabular}{ccc|}
$\begin{array}{c}\text { Organic fiber } \\
\text { (wt.\%) }\end{array}$ & $\begin{array}{c}\text { Porosity } \\
(\%)\end{array}$ & $\begin{array}{c}\text { Strength } \\
(\mathrm{MPa})\end{array}$ \\
0 & 25 & 5.25 \\
0.5 & 29 & 4.12 \\
1 & 34 & 3.53 \\
1.5 & 39 & 2.33 \\
\hline
\end{tabular}

\subsection{Experimental validation}

Through the above simulation analysis and shell optimization, TiAl alloy turbochargers were cast with a shell mould containing $1 \mathrm{wt} . \%$ organic fibers, a mould preheating temperature of $600{ }^{\circ} \mathrm{C}$, and a centrifugal rotational rate of $200 \mathrm{rpm}$. Figure 6 (a) shows the appearance of the turbocharger wheels produced. Compared to the castings before optimization, the forming integrity was improved dramatically, but the surface quality needed further improvement because interface reaction still existed. Fluorescence detection shows no linear indication, which suggested no crack was detectable. Figure 6(b) shows inner quality examined by X-ray detection, and no misruns and gas holes can be found.

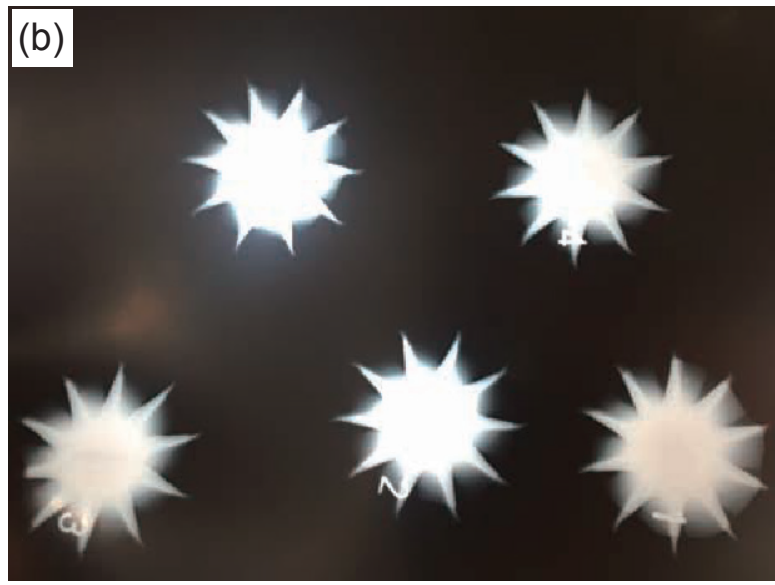

Fig. 6: TiAl alloy turbocharger wheels prepared after process optimization: (a) Appearance of TiAl alloy turbocharger wheels; (b) X-ray detection results of the castings 


\section{Discussion}

Ti-46Al-6.5Nb-0.6Cr-0.2Ni alloy has a wide temperature range of crystallization due to high $\mathrm{Al}$ content. Meanwhile, high $\mathrm{Nb}$ content would increase the liquidus and solidus (Fig. 7), leading to a poor fluidity of this alloy, so a turbocharger wheel was difficult to cast with a conventional process. In this study, process optimization was carried out from the viewpoint of mould filling, which can be divided into three steps. Firstly, the melt flow was pure liquid before the superheat was thoroughly lost [Fig. 8(a)]. Then, the liquid temperature fell below liquidus, crystals nucleated at the front of liquid flow [Fig. 8(b)], crystals grew up as liquid went ahead, and viscosity of the flow increased. Finally, dendritic crystals formed a net through which liquid metal could not pass [Fig. 8(c)]. If the mould has residual gas, it will also prevent the liquid moving on. Therefore, misrun and gas holes are easily formed for TiAl alloy castings. In order to eliminate the two kinds of defects, mould preheating, centrifugal casting, and permeable shell mould were all needed to obtain integrated castings. Firstly, centrifugal force can increase the running distance of pure liquid in the first step. Secondly, mould preheating can weaken the heat loss and increase running distance during the second step. Lastly, porous shell mould with acceptable strength was designed for residual gas to penetrate, which was indispensable for thin-walled castings produced under a protective gas atmosphere.

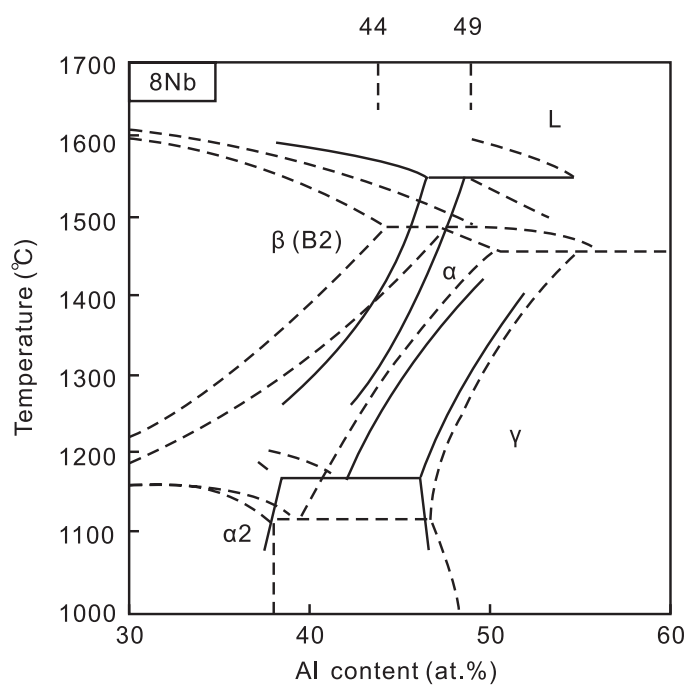

Fig. 7: $8 \mathrm{Nb}$-TiAl alloy quasi binary phase diagram ${ }^{[31]}$

(a)

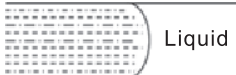

(b)

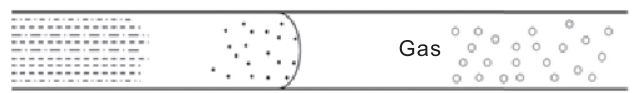

(c)

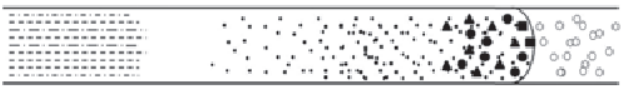

Fig. 8: Illustration of filling process of thin-wall casting

\section{Conclusions}

(1) Casting parameters of TiAl alloy turbocharger wheels are optimized based on numerical simulation. A mould preheating temperature of $600{ }^{\circ} \mathrm{C}$ and centrifugal rotational rate of $200 \mathrm{rpm}$ are selected to obtain the balanced filling and feeding capacities.

(2) To enhance gas permeability of the shell mould, organic fibers are added into the back layers. The porosity of the shells increases from $25 \%$ to $39 \%$ with the increase of organic fibers from 0 to $1.5 \mathrm{wt} . \%$, while the shell strength decreases from 5.25 $\mathrm{MPa}$ to $2.33 \mathrm{MPa}$. The shell with 1wt.\% fibers was optimal for the casting experiment in this study.

(3) Integrated TiAl alloy turbochargers are finally produced free of gas holes and misruns. The experimental results proved that the process optimization is effective for a single wheel casting.

\section{Acknowledgements}

This work was financially supported by the Liaoning Natural Science Foundation (Grant No. 20170540888), and the Liaoning Science and Technology Project (Grant No. 2017221006).

\section{References}

[1] Kim Y W, Dimiduk D M. Designing gamma TiAl alloys: fundamentals, strategy and production in structural intermetallics. Nathal M V, Darolia R, Liu C T, et al, eds., TMS, Warrendale, PA, 1997: 531-543.

[2] Hu D, Wu X, Loretto M H. Advances in optimization of mechanical properties in cast TiAl alloys. Intermetallics, 2005, 13: 914-919.

[3] Appel F, Wagner R. Microstructure and deformation of twophase $\mathrm{Y}$-titanium aluminides. Materials Science and Engineering R, 1998, 22: 187-268.

[4] Yamaguchi M, Inui H. TiAl compounds for structural applications in structural intermetallics. Darolia R, Liu C T, Martin P L, et al., eds., TMS, Warrendale, PA, 1993: 127-142.

[5] Loria E A. Gamma titanium aluminides as prospective structural materials. Intermetallics, 2000, 8: 1339-1345.

[6] Paul J D H, Appel F, Wagner R. The compression behaviour of niobium alloyed $\gamma$-titanium aluminides. Acta Materialia, 1998, 46: 1075-1085.

[7] Chen G L, Wang J G, Ni X D, et al. A new intermetallic compound in $\mathrm{TiAl}+\mathrm{Nb}$ composition area of the Ti-Al-Nb ternary system. Intermetallics, 2005, 13: 329-336.

[8] Hecht U, Witusiewicz V, Drevermann A, et al. Grain refinement by low boron additions in niobium-rich TiAl-based alloys. Intermetallics, 2008, 16: 969-978.

[9] Hu D, Huang A J, Novovic D, et al. The effect of boron and alpha grain size on the massive transformation in Ti-46Al-8NbxB alloys. Intermetallics, 2006, 14: 818-825.

[10] Saage H, Huang A J, Hu D, et al. Microstructures and tensile properties of massively transformed and aged Ti46Al8 $\mathrm{Nb}$ and Ti46Al8Ta alloys. Intermetallics, 2009, 17: 32-38.

[11] Huang $Z$ W, Cong T. Microstructural instability and embrittlement behaviour of an Al-lean, high-Nb gamma-TiAl-based alloy subjected to a long-term thermal exposure in air. Intermetallics, 2010, 18: 161-172. 
[12] Gerling R, Bartels A, Clemens H, et al. Structural characterization and tensile properties of a high niobium containing gamma TiAl sheet obtained by powder metallurgical processing. Intermetallics, 2004, 12: 275-280.

[13] Bystrzanowski S, Bartels $\mathrm{A}$, Clemens $\mathrm{H}$, et al. Characteristics of the tensile flow behavior of Ti-46Al-9Nb sheet materialanalysis of thermally activated processes of plastic deformation. Intermetallics, 2008, 16: 717-726.

[14] Stark A, Bartels A, Clemens $\mathrm{H}$, et al. On the formation of ordered $\omega$-phase in high $\mathrm{Nb}$ containing $\mathrm{y}$-TiAl based alloy. Advanced Engineering Materials, 2008, 10: 929-934.

[15] Jabbar H. Microstructure and mechanical properties of high niobium containing TiAl alloys elaborated by spark plasma sintering. Intermetallics, 2010, 18: 2312-2321.

[16] Kim Y W. Wrought TiAl alloy design. Transactions of Nonferrous Metals Society of China, 1999, 9: 298.

[17] Blackburn M J, Smith M P. Titanium alloys of the TiAltype: US Patent: 4294615. 1981: 10-13.

[18] Sheng W B. Filling and solidification of TiAl melt in centrifugal field. Transactions of Nonferrous Metals Society of China, 2006, 16: s719-s722.

[19] Gomes F, Barbosa J, Ribeiro C S. Induction melting of $y$-TiAl in CaO crucibles. Intermetallics, 2008, 16: 1292-1297.

[20] Liu A H, Li B S, Nan H, et al. Study of interfacial reaction between TiAlalloys and four ceramic molds. Rare Metal Materials and Engineering, 2008, 37(6): 0956-0959.

[21] Wang S R, Guo P Q, Yang L Y. Centrifugal precision cast TiA turbocharger wheel using ceramic mold. Journal of Materials Processing Technology, 2008, 204: 492-497.

[22] Mi G F, Liu X Y, Wang K F, et al. Application of numerica simulation technique to casting process of valve block. Journal of Iron and Steel Research, International, 2009: 16(4): 12-17.
[23] Ramanujan R V, Maziasz P J, Liu C T. The thermal stability of the microstructure of $y$-based titanium aluminides. Acta Materialia, 1996, 44: 2611-2642.

[24] Kothari K, Radhakrishnan R, Wereley N M. Advances in gamma titanium aluminides and their manufacturing techniques. Progress in Aerospace Sciences, 2012, 55:1-16.

[25] Yang L, Chai L H, Liang Y F, et al. Numerical simulation and experimental verification of gravity and centrifugal investment casting low pressure turbine blades for high $\mathrm{Nb}-\mathrm{TiAl}$ alloy. Intermetallics, 2015, 66: 149-155.

[26] Su Y Q, Guo J J, Jia J, et al. Centrifugal investment casting of a TiAl-based Turbine blade. Rare Metal Materials and Engineering, 2002, 31: 295-298.

[27] Wan Y B. Study on investment casting defects of TiAl alloy. Harbin: Harbin Institute of Foundry, 2009: 1-7. (In Chinese)

[28] Pedro C G O, Gelson L A, Ricardo F R, et al. The effect of mold temperature on castability of $\mathrm{CP} \mathrm{Ti}$ and $\mathrm{Ti}-6 \mathrm{Al}-4 \mathrm{~V}$ castings into phosphate bonded investment materials. Dental Materials, 2006, 22: 1098-1102.

[29] Aguilar J, Schievenbusch A, Kattlitz O. Investment casting technology for production of TiAl low pressure turbine bladesProcess engineering and parameter analysis. Intermetallics, 2011, 19(6): 757-761.

[30] Shangguan H, Kang J, Yi J, et al. Controlled cooling of an aluminum alloy casting based on 3D printed rib reinforced shell mold. China Foundry, 2018, 15: 210-215.

[31] Chen G L, Zhang W J, Liu Z C, et al. Microstructure and properties of high-Nb containing TiAl-base alloys. In: Kim Y W, Dimiduk D M, Loretto M H, eds., Gamma Titanium Aluminides 1999, Warrendale, PA: TMS, 1999: 31. 